\title{
SEASONAL TRENDS IN TIBETAN LAKE LEVEL CHANGES AS OBSERVED BY ICESAT LASER ALTIMETRY
}

\author{
V.H.Phan", R.Lindenbergh, M.Menenti \\ Department of Remote Sensing, Delft University of Technology, 2600 GB Delft, The Netherlands \\ (V.Phanhien, R.C.Lindenbergh, M.Menenti)@tudelft.nl
}

KEY WORDS: LIDAR, satellite, change detection, hydrology, climate, understanding

\section{ABSTRACT:}

The Tibetan plateau is covered by hundreds of larger and smaller lakes. Until recently there was no method to monitor their water level variations due to lack of in-situ measurements or unfitness of available remote sensing methods. However the ICESat/GLA14 laser altimetry data provide global surface elevations for land during 18 one-month campaigns between 2003 and 2009. This product could be used to accurately monitor water level variations and to estimate annual water level trends of about 150 Tibetan lakes. Based on the ICESat campaign schedule, lake levels derived from the GLA14 data are classified into three groups referenced to the Tibetan seasons: late dry, early wet, and early dry. For each lake sampled by sufficient ICESat campaigns, seasonal water level trends could be estimated and inter-seasonal lake level variations could be determined. The results indicate that most of the southern Tibetan lakes have a downward seasonal trend while most lakes elsewhere in Tibet have a positive seasonal trend. This means that these seasonal trends are similar to the annual trends. Moreover, lake level variations between seasons are much larger in the south than in the north and the west of Tibet. Based on the spatial pattern of the lakes, the Tibetan plateau is divided into four sub-areas corresponding to seasonal lake level trends and inter-seasonal lake level variations. The results confirm climatic trends as discussed in meteorological literature. Therefore, this analysis is expected to improve the understanding of the limnological processes on the Tibetan plateau and their impacts on the surrounding regions.

\section{INTRODUCTION}

The Tibetan Plateau is not only the highest and largest plateau of the world but is also called the Third Pole as it stores a large amount of ice in its thousands of glaciers. It is the source of all major rivers in South-East Asia, the most densely populated region on Earth. As mentioned in (Immerzeel et al., 2010), more than 1.4 billion people depend for their living and food security on water from the Tibetan lakes and rivers. Observing the changes in the water levels of Tibetan lakes could provide essential information to understand the characteristics of the Tibetan climate, its changes and its impact on the surrounding densely populated regions.

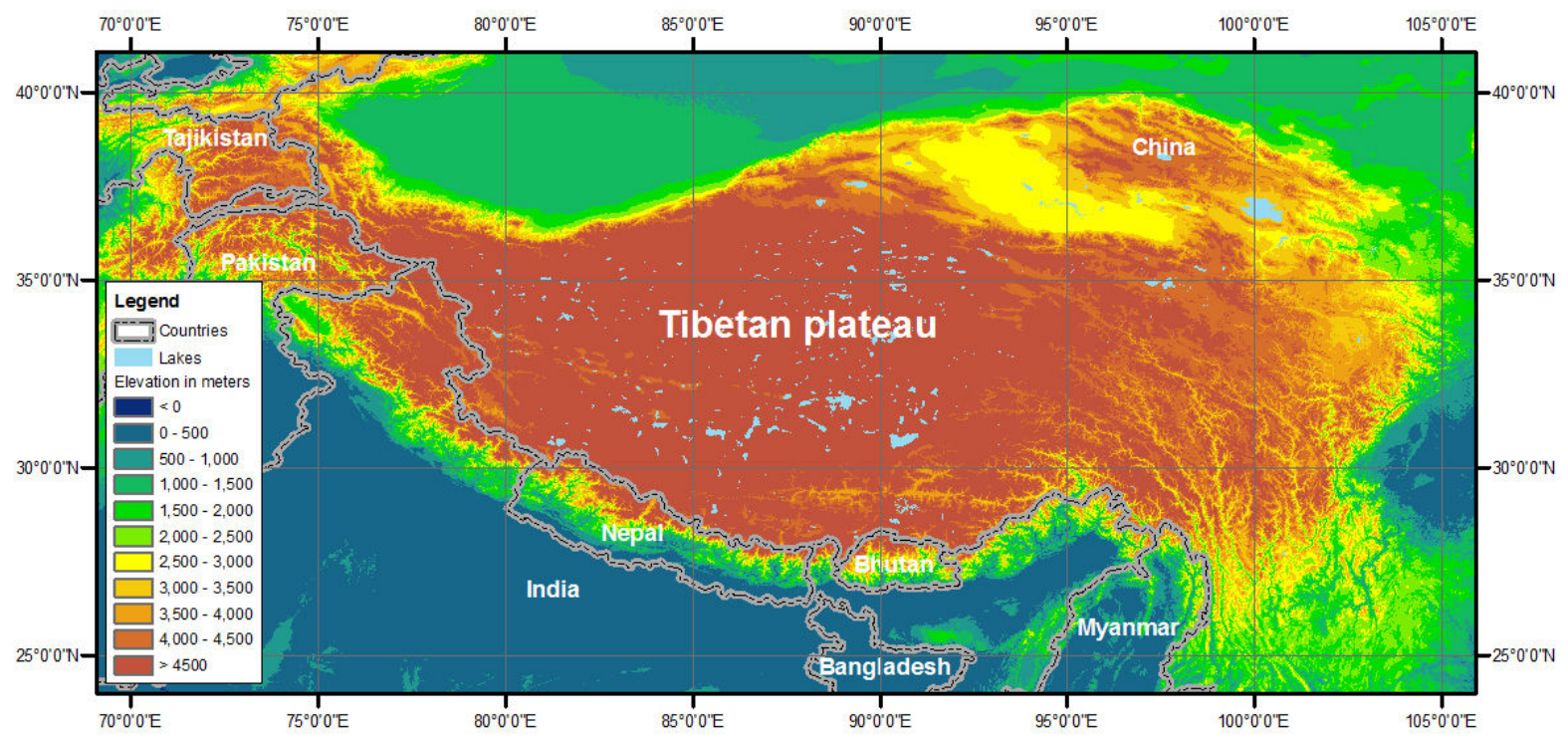

Figure 1. The Tibetan plateau

Roughly, there are two different seasons in Tibet: the dry season, winter, and the wet or rainy season, summer. Most of the annual rainfall occurs between May and September, when the Tibetan plateau is influenced by the Indian and East Asian monsoons, as mentioned in (Zhisheng et al, 2001). According to (Kang et al, 2010) the Tibetan plateau is affected by significant warming for the last decades and will continue to warm in future. In addition, (Tao et al., 2004) concluded that the south of Tibet becomes warmer and wetter with a clear increase in rainfall as well, while a part of the north turns 
warmer and drier. The center of Tibet is reported to become warmer and more humid as well, but here the increase in rainfall is insignificant. Therefore climate and its changes are not the same for different sub-areas on the Tibetan plateau.

Between 2003 and 2009 the Geoscience Laser Altimeter System (GLAS) on board of the Ice, Cloud and land Elevation Satellite (ICESat) obtained world-wide elevation profiles during 18 one-month campaigns (NASA, 2011). Using the GLAS data it is possible to accurately observe water level variations of Tibetan lakes, as described in (Phan et al., 2011) and (Zhang et al., 2011). (Phan et al., 2011) used the obtained lake level variations between 2003 and 2009 of 154 lakes over one square kilometer to determine annual water level trends for each lake. It was concluded that most of the lakes with a clearly downward trend are in the South of the Tibetan plateau and along the Himalaya mountain range and, vice versa, most of the lakes with a positive water level trend are on the inner Tibetan plateau. However, the ICESat data not only enables the computation of annual lake level trends but also shows clearly seasonal differences. This paper focuses on these seasonal differences.

\section{METHODS}

Following the processing to obtain lake levels as described in (Phan et al., 2011), a set of mean elevations per pass over ordered by acquisition time between 2003 and 2009 was generated for each of the 154 observed Tibetan lakes. The lake levels were derived from Release 31 ICESat/GLA14 data (NSIDC, 2011) while locations of the Tibetan lakes were determined based on the MODIS land-water mask (GLCF, 2011). A mean elevation representative for a lake surface at the corresponding UTC time was the average of elevations of the ICESat/GLAS footprints completely within the lake with a standard deviation of maximal $15 \mathrm{~cm}$. Subsequently the dataset of mean elevations is analyzed to represent seasonal water level variations of the Tibetan lakes during the observing period.

\subsection{Estimating seasonal lake level trends}

\begin{tabular}{|c|c|c|c|c|c|c|c|c|c|c|c|c|}
\hline Tibetan season & \multicolumn{4}{|c|}{ Dry } & \multicolumn{5}{|c|}{ Wet } & \multicolumn{3}{|c|}{ Dry } \\
\hline Month & 1 & 2 & 3 & 4 & 5 & 6 & 7 & 8 & 9 & 10 & & 12 \\
\hline Defined season & & & है है & & ॄ. & & & & & & & \\
\hline $\begin{array}{c}\text { ICESat/GLAS } \\
\text { campaign }\end{array}$ & & & 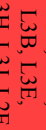 & & 5 & & & & & & & \\
\hline
\end{tabular}

Table 1. Classifying the ICESat/GLAS campaigns based on the Tibetan seasonal characteristics

According to the ICESat/GLAS campaign schedule (NSIDC, 2011), for each lake the dataset of mean elevations is divided into 3 different seasonal groups: late dry, early wet and early dry, related to the Tibetan seasons as shown in Table 1. A seasonal lake level trend for a certain season is estimated by linear regression if the lake is sampled by at least three campaigns in that season. The slope of the seasonal trend indicates the rate of the seasonal lake level change per year while the RMSE (Root Mean Square Error), as a standard deviation of residuals, consists of a combination of possible data errors and mainly the inaccuracy of the linear regression model. Estimating a lake level trend based on only three campaigns can be applied because the mean elevations have relatively high confidences with a standard deviation of maximal $15 \mathrm{~cm}$. Besides potential useful information is lost if all trends based on three lake levels are removed. Therefore it is chosen to include these trends. Further confidence in individual elevation levels is also obtained by comparisons to in-situ data at Nam Tso (Zhang et al., 2011) or to radar altimetry data at Qinghai Tso and Selin Tso (Phan et al., 2011). In Figure 2, it indicates that the water level at Palku Tso Lake has a yearly decrease of $13.9 \mathrm{~cm}$ between late dry seasons with a RMSE of $6.5 \mathrm{~cm}$, of $17.8 \mathrm{~cm}$ between wet seasons with a RMSE of 9.7 $\mathrm{cm}$, and of $16.3 \mathrm{~cm}$ between early dry seasons with a RMSE of $8.7 \mathrm{~cm}$. Therefore, for each Tibetan lake sampled by sufficient ICESat campaigns, at most three water level trends corresponding to the three defined seasons between 2003 and 2009 are obtained.

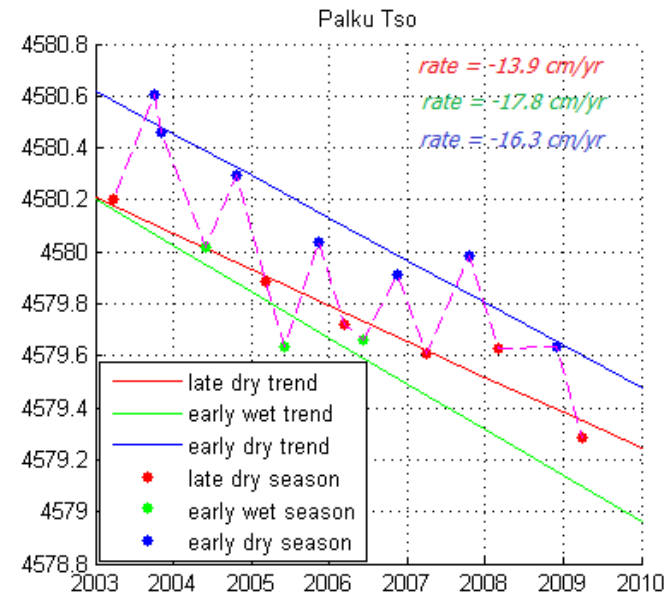

Figure 2. Seasonal water level trends for Palku Tso Lake between 2003 and 2009

\subsection{Obtaining seasonal differences in lake level}

Following the seasonal groups as described in Table 1, the dataset of the mean elevations of each lake during the 7 year observing period could be arranged into an array storing 21 seasonal values in sequence: late dry, early wet, early dry, and so on. It is noted that all 21 defined seasons were not covered by ICESat data as ICESat only had 18 campaigns. Each of the 21 values represents an average height of the lake surface corresponding to the defined season. If a lake was sampled by more than one ICESat track during any defined season, the average value of the mean elevations is assigned to an array element. For example, at the Palku Tso Lake as shown in Figure 2, the average value of the two lake levels in the early dry season in 2003 is considered representative for the seasonal lake surface. The array of the seasonal Palku Tso lake level is shown in Table 2, where the null value means that the lake surface was not sampled by ICESat during that defined season.

Based on the elevation array, a difference in seasonal lake levels between the defined seasons could be obtained. Because there were only three campaigns (L2C, L3C, and L3F) in the early wet seasons, differences in lake level with respect to these campaigns are not considered in the following. Thus two cases in which inter-seasonal water level variations are considered consist of the difference between the late dry season and the 
consecutive early dry season in the same calendar year, corresponding to the $\Delta_{1}$ column of Table 2 , and the difference between the early dry season and the late dry season of next calendar year, the $\Delta_{2}$ column of Table 2 . The $\Delta_{1}$ value indicates the water level change during the monsoon while the $\Delta_{2}$ value indicates the water level change during the dry season. For example, as illustrated in Table 2, the Palku Tso lake level increased by $15 \mathrm{~cm}$ during the monsoon in 2005 , while it lost $32 \mathrm{~cm}$ during the dry season from 2005 to 2006 .

\begin{tabular}{|c|c|c|c|c|}
\hline Id & Year & $\begin{array}{c}\text { Average } \\
\text { height }(\mathrm{m})\end{array}$ & $\Delta_{\mathrm{l}}(\mathrm{m})$ & $\Delta_{2}(\mathrm{~m})$ \\
\hline 1 & \multirow{3}{*}{2003} & 4579.90 & \multirow{3}{*}{0.63} & \\
\hline 2 & & null & & \\
\hline 3 & & 4580.53 & & \multirow{2}{*}{ null } \\
\hline 4 & \multirow{3}{*}{2004} & null & \multirow{3}{*}{ null } & \\
\hline 5 & & 4580.02 & & \\
\hline 6 & & 4580.30 & & \multirow{2}{*}{-0.41} \\
\hline 7 & \multirow{3}{*}{2005} & 4579.89 & \multirow{3}{*}{0.15} & \\
\hline 8 & & 4579.63 & & \\
\hline 9 & & 4580.04 & & \multirow{2}{*}{-0.32} \\
\hline 10 & \multirow{3}{*}{2006} & 4579.72 & \multirow{3}{*}{0.19} & \\
\hline 11 & & 4579.66 & & \\
\hline 12 & & 4579.91 & & \multirow{2}{*}{-0.31} \\
\hline 13 & \multirow{3}{*}{2007} & 4579.61 & \multirow{3}{*}{0.38} & \\
\hline 14 & & null & & \\
\hline 15 & & 4579.98 & & \multirow{2}{*}{-0.36} \\
\hline 16 & \multirow{3}{*}{2008} & 4579.63 & \multirow{3}{*}{0.01} & \\
\hline 17 & & null & & \\
\hline 18 & & 4579.64 & & \multirow{2}{*}{-0.36} \\
\hline 19 & \multirow{3}{*}{2009} & 4579.28 & \multirow{3}{*}{ null } & \\
\hline 20 & & null & & \\
\hline 21 & & null & & \\
\hline & \multicolumn{2}{|c|}{ Average } & 0.27 & -0.35 \\
\hline
\end{tabular}

Table 2. The seasonal elevation array and water level differences between defined seasons of the Palku Tso lake

An average water level difference between the defined seasons is also obtained, by taking the average of all available differences. The $\overline{\Delta_{1}}$ value indicates the average lake level difference during the monsoon while $\overline{\Delta_{2}}$ indicates the average lake level difference during the dry season. For instance, between 2003 and 2009 at Palku Tso Lake the water level increases on average by $27 \mathrm{~cm}$ during the monsoon, while it has an average decrement of $35 \mathrm{~cm}$ in the dry season.

\section{RESULTS}

\subsection{Seasonal lake level trends all over the Tibetan plateau}

In total 121 trends for the late dry season, 41 trends for the early wet season and 123 trends for the early dry season of lake level change over the Tibetan plateau could be estimated. The result also indicates that RMSEs of the seasonal water level trends less than $30 \mathrm{~cm}$ are $86 \%$ of the 121 lakes observed between late dry seasons, $88 \%$ of the 41 lakes between early wet seasons, and $57 \%$ of the 123 lakes between early dry seasons. Lake level variations between early dry seasons are relatively large because they were samples from September to December, as described in Table 1. Actually most of the seasonal water level trends of the observed lakes are similar to the annual trends. This means that most of the observed lakes on the southern Tibetan plateau and along the Himalaya mountain ranges, belonging to the Brahmaputra, Ganges and Indus basins, have a serious downward seasonal water level trend while most of the observed lakes of the rest of the Tibetan plateau have a positive seasonal trend. As shown in Figures 3a and $3 b$, the blue and red lakes have seasonal trends with the same sign as the annual trends while the trends of the green and orange lakes behave in the opposite way. The results indicate that $15.7 \%$ of the number of lake levels for the late dry season in Figure $3 \mathrm{a}$ or only $10.6 \%$ of the number of lake levels for the early dry season in Figure $3 \mathrm{~b}$ is trending opposite of their annual trend.

\subsection{Lake level differences during the monsoon and during the dry season}

After calculating average lake level differences between two defined seasons, the observed lakes are classified into five groups and colored as represented in Figures $4 \mathrm{a}$ and $4 \mathrm{~b}$. The range of $+/-15 \mathrm{~cm}$ indicates that a lake level only varies little, symbolized as the green lakes. The red and orange lakes indicate a water level decrement while the blue and cyan lakes indicate a water level increment.

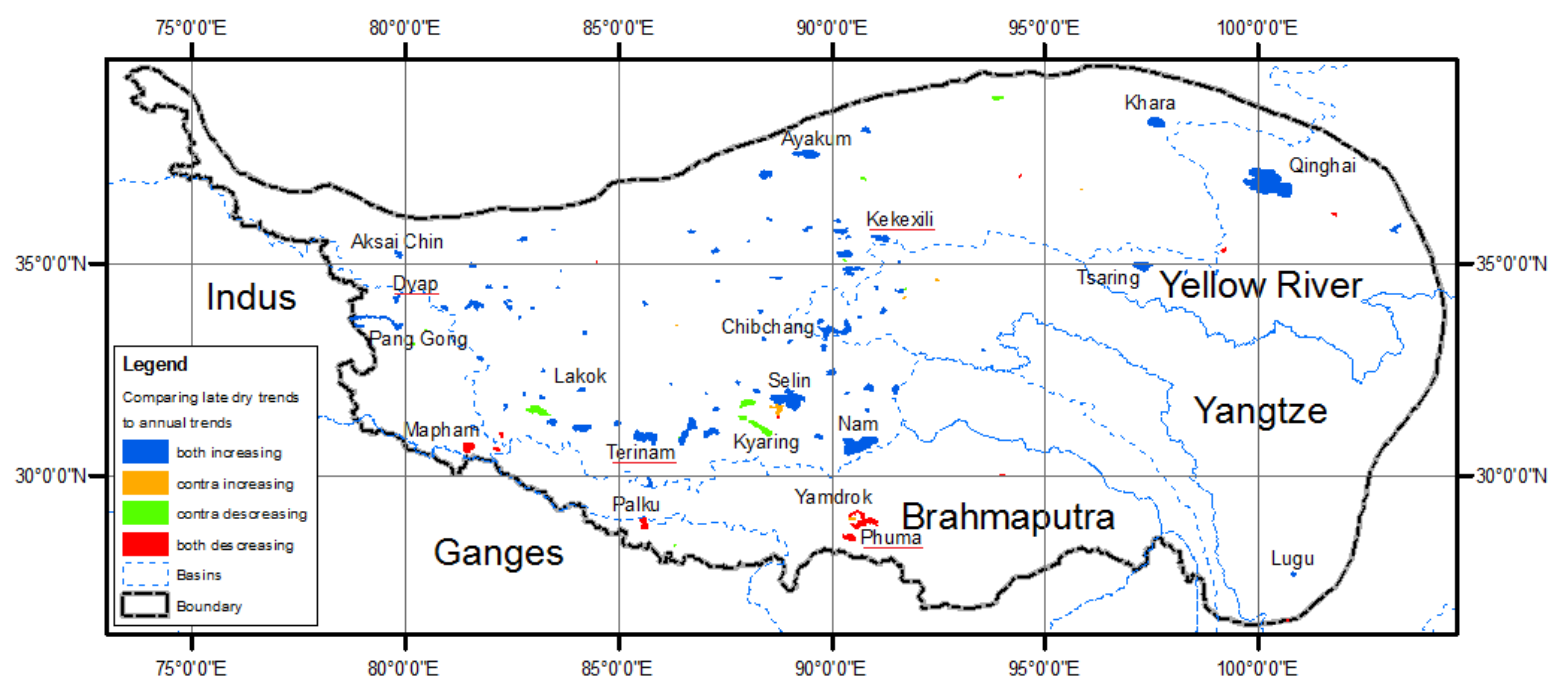

Figure 3a. Comparing late dry to annual water level trends of the Tibetan lakes between 2003 and 2009 


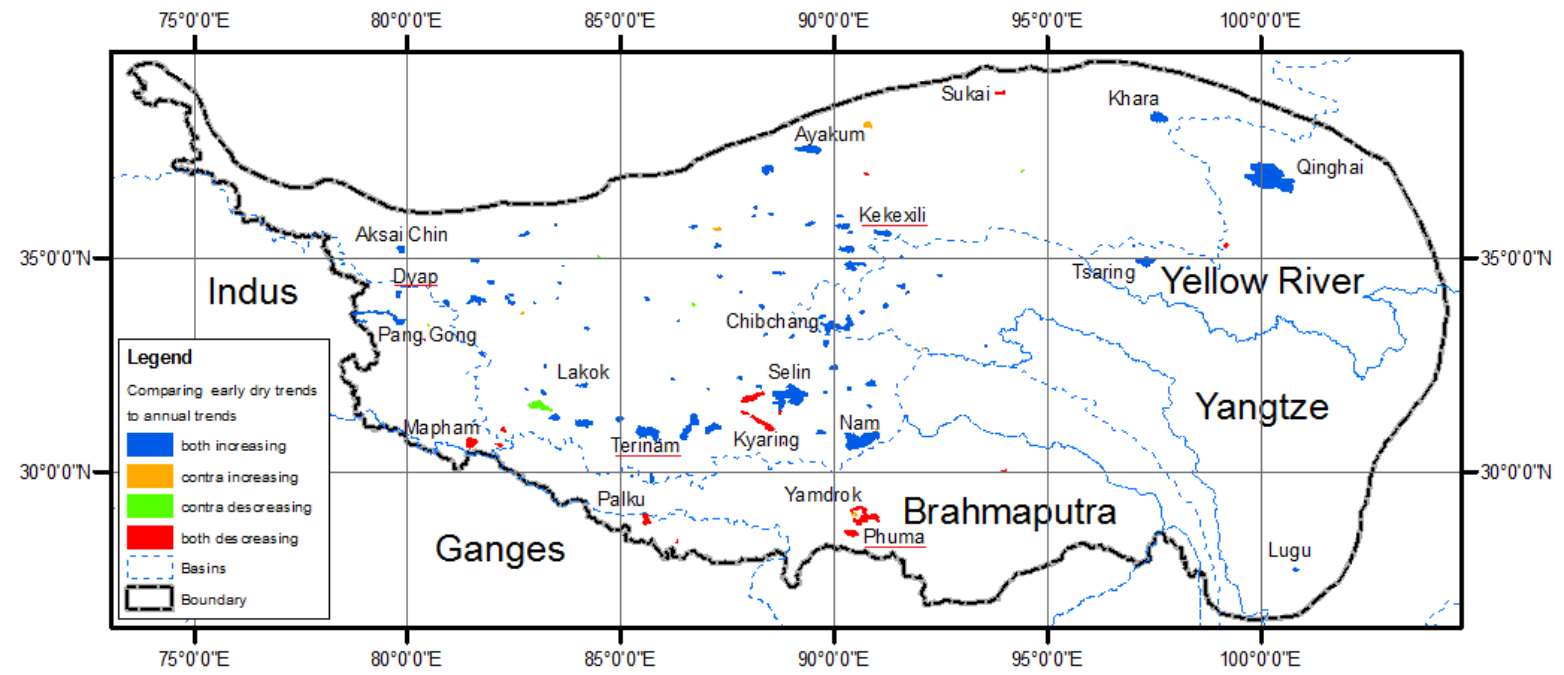

Figure 3b. Comparing early dry to annual water level trends of the Tibetan lakes between 2003 and 2009

As a result, the $\overline{\Delta_{1}}$ values of 125 lakes on the Tibetan plateau can be obtained, indicating the average lake level differences during the monsoon between 2003 and 2009, as shown in Figure $4 \mathrm{a}$. The result shows that $51.2 \%$ of the 125 lakes have a water level increase while $24 \%$ of these lake levels decrease. In addition $24.8 \%$ of these lakes are considered as invariable water levels. Most of the blue and cyan lakes having a water level increment are located on the east and the south of Tibet, while the red and orange lakes are located on the west of Tibet, belonging to the Indus basin, and sparsely from the northeast to the northwest of Tibet, as illustrated in Figure 4a. Moreover the southern Tibetan lakes have an obvious water level increment and these differences gradually decrease from the south to the north and the northwest of Tibet.
Besides, the average Tibetan lake level differences during the dry season between 2003 and 2009, corresponding to the $\overline{\Delta_{2}}$ values are illustrated in Figure $4 \mathrm{~b}$. The result shows that $46.4 \%$ of the 138 observed lake levels are in the range of $+/-15 \mathrm{~cm}$. Furthermore $22.4 \%$ have a decrease while $31.2 \%$ have an increase over $15 \mathrm{~cm}$. In addition, a strong water level decrement occurs in the south of Tibet while lake levels in the center of Tibet are nearly invariable as shown in Figure 4b. A quick drainage takes place at a few lakes in the inner plateau. The lakes having a significant water level increment are at the west of Tibet and belong to the Indus basin. In addition a few increasing lakes are located in the north of Tibet. Moreover, most of the red and orange lakes in Figure 4a, having a water level decrement during the monsoon, change into green, cyan or blue lakes in Figure $4 \mathrm{~b}$, being nearly invariable or having a water level increment during the dry season.

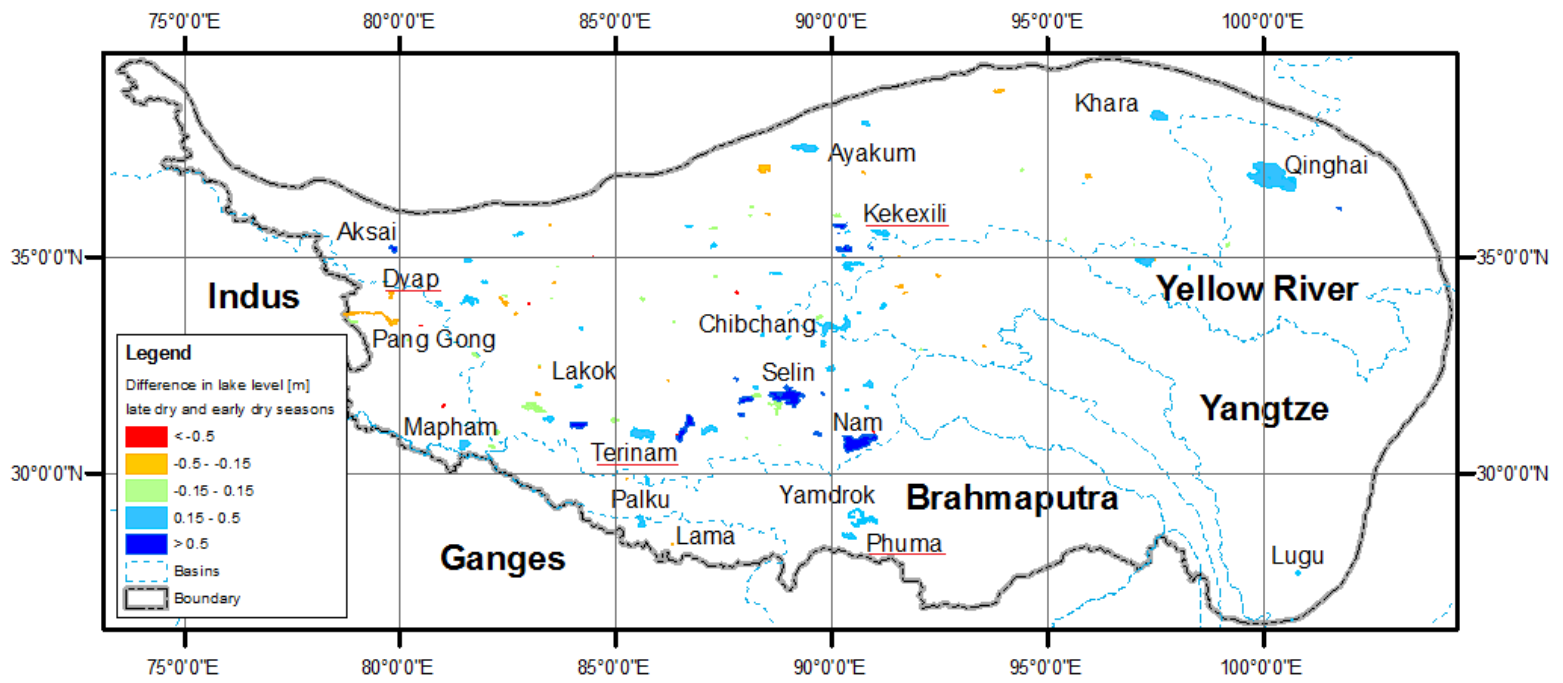

Figure 4a. Average lake level differences during the monsoon on the Tibetan plateau between 2003 and 2009 
ISPRS Annals of the Photogrammetry, Remote Sensing and Spatial Information Sciences, Volume I-7, 2012

XXII ISPRS Congress, 25 August - 01 September 2012, Melbourne, Australia

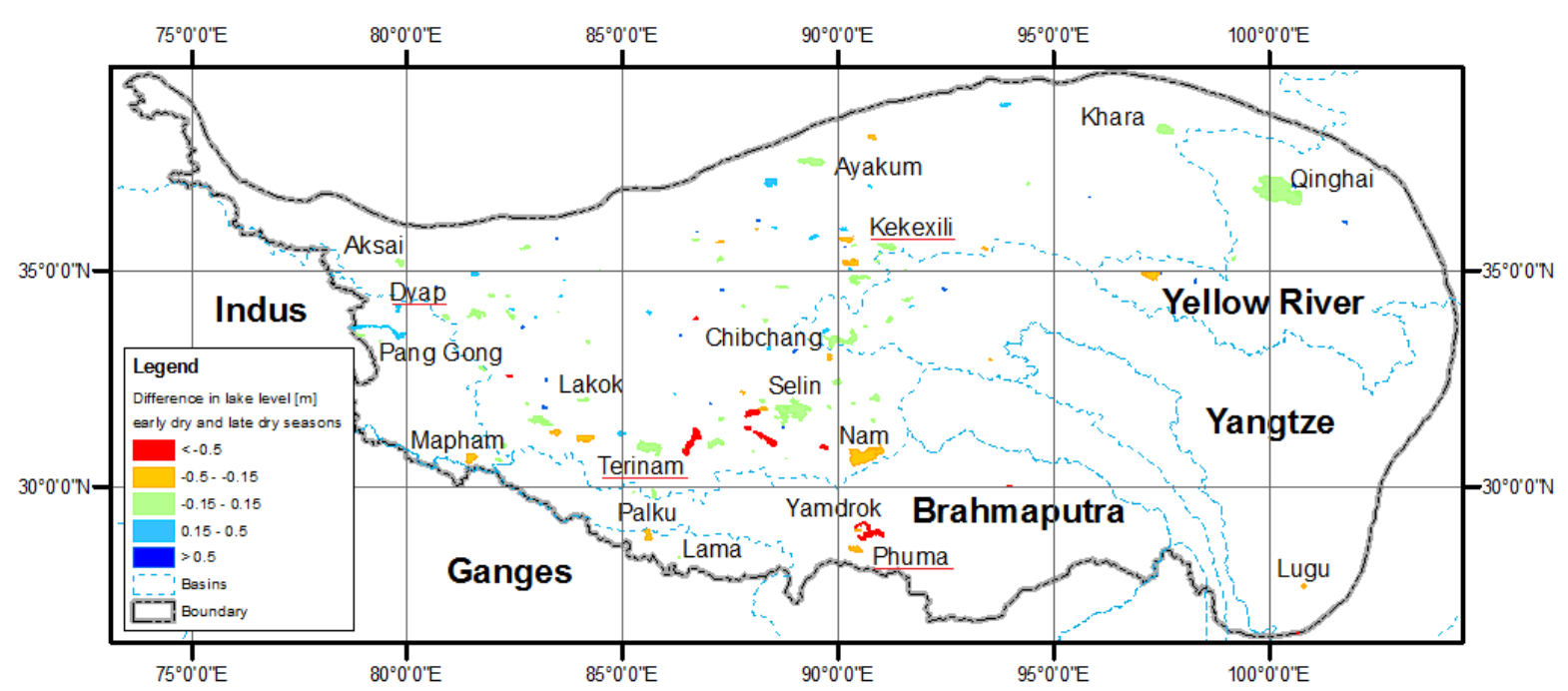

Figure 4b. Average lake level differences during the dry season on the Tibetan plateau between 2003 and 2009

\subsection{Case studies}

Based on the seasonal trends and the inter-seasonal lake level variations, spatial patterns of observed Tibetan lakes could be determined. Accordingly the Tibetan plateau is divided into four sub-areas where the lakes have the same characteristics. The first group of lakes is in the south of Tibet and belongs to the Brahmaputra, Ganges and Indus basins, e.g. Lugu Tso,
Phuma Tso, Yamdrok Tso, Palku Tso, Mapham Tso, etc. The second group is in the south and belongs to the inner plateau, e.g. Selin Tso, Terinam Tso, Lakok Tso, etc. The third group is in the center and upwards to the north, e.g. Qinghai Tso, Khara Tso, Kekexili Tso, Ayakum Tso, Charol Tso, Aksai Tso, etc. Finally the fourth group is in the west and belongs to the Indus basin, e.g. Pang Gong Tso, Dyap Tso, etc.
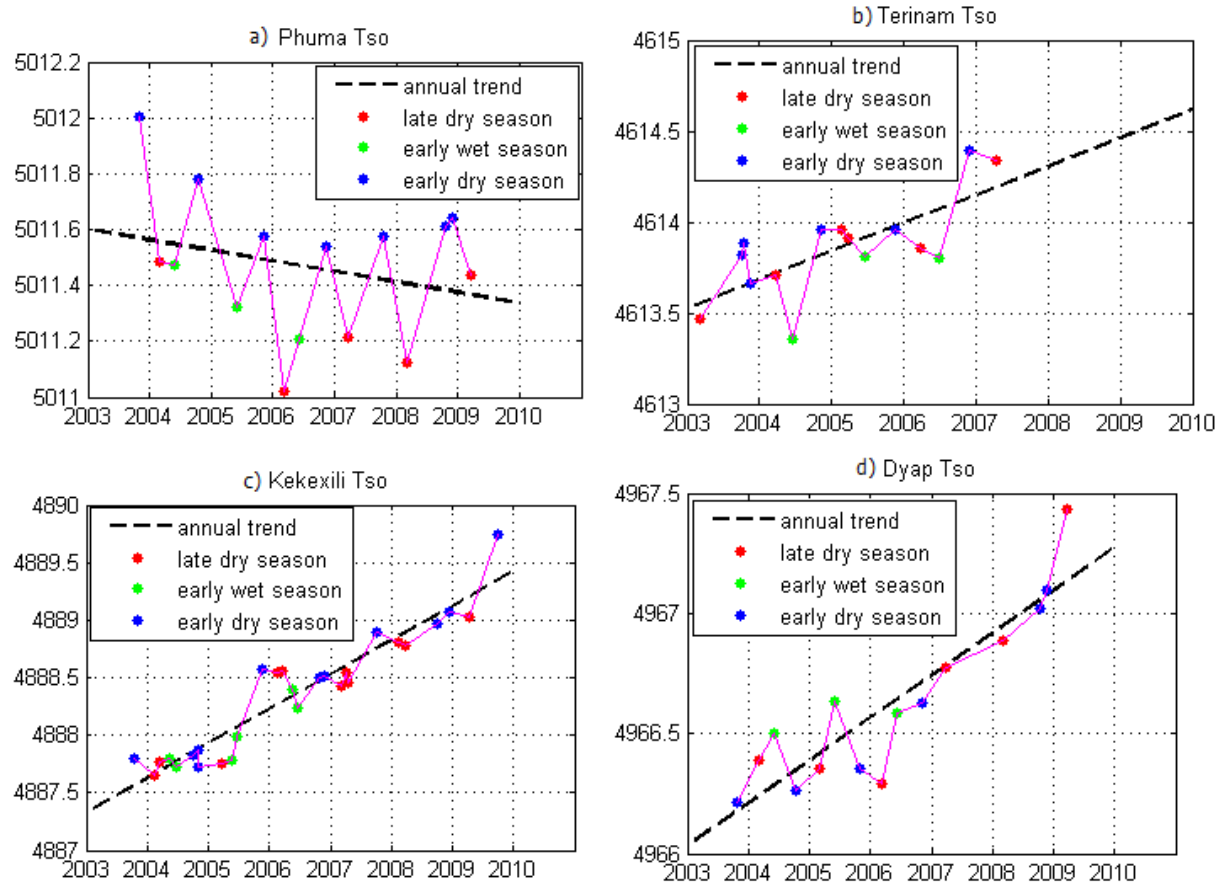

Figure 5. Typical seasonal lake level variations at selected lakes in sub-areas on the Tibetan plateau between 2003 and 2009

Firstly in the south of Tibet and belonging to the Brahmaputra, Ganges and Indus basins, most of the observed lakes have a remarkable downward seasonal water level trend, similar to their annual trend. However the lakes always have much higher lake levels in the early dry season than in the late dry season.
The lake levels increase clearly during the start of monsoon and decrease quickly during the dry season as illustrated for the Phuma Tso lake in Figure 5a). These lakes seem strongly affected by the annual Indian and Asian monsoons. 
Secondly in the south of Tibet and belonging to the inner plateau, most of the observed lakes have a positive seasonal water level trend, similar to their annual trend. Nevertheless the lake level difference during the monsoon is much larger than that during the Tibetan dry season. The lake levels are nearly invariable or decrease only a little in the dry season. The Terinam Tso lake could be representative for this sub-area, compare Figure $5 b$ ). This sub-area seems also influenced by the annual monsoons.

Thirdly in the center and upwards to the north of Tibet, most of the lakes have the same tendency as the second group. Their seasonal lake level trends mostly are positive and their water levels increase after the annual rainfalls. However the lake level differences during the monsoon are smaller and gradually decrease from the southeast to the northwest. The Kekexili Tso lake as shown in Figure 5c) is considered typical for this subarea. Nevertheless this sub-area sparsely contains some lakes having the same characteristics as the lakes discussed in the following.

In the west of Tibet and belonging to the Indus basin, most of the lakes have a small upward seasonal water level trend, similar to their annual trend. The average lake level differences during the monsoon are negative, while those during the dry season are positive. These mean that lake levels decrease during the monsoon season while they increase in winter. The lake level variation for the Dyap Tso lake is represented in Figure $5 d)$.

\subsection{Discussion}

As described in the results above, the seasonal trends and interseasonal water level variations of the observed lakes between 2003 and 2009 are confirming the climatic trend on the Tibetan plateau mentioned in recent research. The lake levels in the south of Tibet clearly increase from the late dry season to the early dry season, probably corresponding to a large amount of precipitation caused annually by the Indian and South Asian monsoons as indicated in (Kang et al., 2010). Inversely most of the lake levels in the west and the north decrease little in the wet or summer season while they increase little or are nearly changeless in the dry or winter season. This confirms the remarks on temperature and humidity as represented in (Tao et al., 2011) that the west and the north of Tibet turn warmer and drier. Moreover, precipitation in the wet season gradually decreases from the southeast to the northwest of the Tibetan plateau as mentioned in (Tao et al., 2004) and (Kang et al., 2010). In addition (Frauenfeld et al., 2005) concluded that temperature in the western plateau is cooler than that in the eastern plateau. These characteristics could affect the lake levels to make the average differences during the monsoon progressively decrease from the southeast to the northwest.

\section{CONCLUSIONS}

The ICESat/GLA14 data can be used to monitor water level variations and to estimate the linear annual trends, but also to obtain seasonal water level trends and inter-seasonal water level variations of the Tibetan lakes. The lakes observed by sufficient GLAS observations are analyzed in two ways, first according to trends per season, and, second, based on the differences in lake level between defined seasons. The result indicates that most of the seasonal water level trends of the Tibetan observed lakes are similar to their annual trends, meaning that most of the southern Tibetan lakes have a serious downward seasonal water level trend while most of the lakes in the inner plateau have a positive trend. Besides, lake level changes differ for four different sub-areas on the Tibetan plateau. Seasonal lake level variations occurring in the south of Tibet are more obvious than those in the northwest. The difference in lake level gradually decreases from the southeast to the northwest of Tibet. These characteristics are corresponding to tendency of precipitation, temperature and humidity documented in recent researches in climatic change at the Tibetan plateau.

\section{Acknowledgements}

The authors would like to thank the National Snow and Ice Data Center for their distribution of the ICESat/GLAS data and the Global Land Cover Faculty for the MODIS land-water mask. This research is partially funded by the CEOP-AEGIS project on the Hydrology and Climatology of the Tibetan Plateau, project no. 212921 of the European Commission FP7 program.

\section{References from Journals:}

Frauenfeld, O.W., Zhang, T., Setteze, M.C., 2005. Climate change and variability using European Centre for MediumRange Weather Forecasts reanalysis (ERA-40) temperatures on the Tibetan plateau, Journal of Geophysical Researsch, Volume 110 D02101 (doi:10.1029/2004JD005230).

Immerzeel, W.W., Van Beek, L.P.H, Bierkens, M.F.P, 2010. Climate change will affect the Asian water towers. Science 328, $1382-1385$.

Kang, S., Xu, Y., You, Q., Flugel, W.A., Pepin, N., Yao, T., 2010. Review of climate and cryospheric change in the Tibetan plateau. Environmental Research Letters, Volume 5015101 (doi:10.1088/1748-9326/5/1/015101).

Phan, V.H, Lindenberg, R.C., Menenti, M., 2011. ICESat derived elevation changes of Tibetan lakes between 2003 and 2009. International Journal of Applied Earth Observation and Geoinformatics (doi:10.1016/j.jag.2011.09.015).

Tao, N., Longxun, C., Zijiang, Z., 2004. The characteristics of climate change over the Tibetan plateau in the last 40 years and the detection of climatic jumps. Advances in Atmospheric Sciences, Volume 21, No. 2, 193 - 203.

Zhang, G.Q., Xie, H.J., Kang, S.C., Yi, D.H., Ackley, S.F., 2011. Monitoring lake level changes on the Tibetan Plateau using ICESat altimetry data (2003-2009). Remote Sensing of Environment, Volume 115, 1733-1742.

Zhisheng A., Kutzbach J.E., Prell W.L., Porter S.C., 2001. Evolution of Asian monsoons and phased uplift of the Himalaya - Tibetan plateau since Late Miocene times. Nature, Vol 411, $62-66$.

\section{References from websites:}

GLCF, MODIS Water Mask. Last visited on August 2011, http://landcover.org/data/watermask

NASA. ICESat homepage. Last visited on November 2011, http://icesat.gsfc.nasa.gov/icesat/

NSIDC. ICESat/GLAS data. Last visited on November 2011, http://nsidc.org/data/icesat/index.html 